\title{
Solvent Extraction the Nitrate of Lanthanide (III) \\ Binary Mixtures Extragents - Carboxylate and Dialkyl Phosphate Amines
}

\author{
Sergey N. Kalyakin, \\ Vladimir I. Kuz'min and Marina A. Mulagaleeva* \\ Institute of Chemistry and Chemical Technology SB RAS \\ 50-24 Academgorodok, Krasnoyarsk, 660036, Russia
}

Received 14.07.2015, received in revised form 26.09.2015, accepted 13.11.2015

The use of binary extractants based on carboxilate and dialkilphosphate of the secondary and tertiary amines and their mixture for separation of ions of lanthanides (III) has been investigated. Isotherms of extraction of lanthanides nitrates (III) are linear at the initial segment, the interphase transfer of cation and anion of an inorganic salt is conjugate, lanthanides reextraction can be carried out by water. Studied binary extractanting agents are characterized by high separation factors of lanthanides. The synergetic effect for the system of di-(2-ethylhexyl)carboxylate, caprinate of di-n-octylammonium and tri-n-octylammonium has been found.

Keywords: REE, binary extraction, carboxylate, amine, di-(2-ethylhexyl)phosphoric acid, synergetic effect.

DOI: 10.17516/1998-2836-2015-8-4-580-589.

(C) Siberian Federal University. All rights reserved

* Corresponding author E-mail address: maral7508@mail.ru 


\section{Извлечение нитратов лантаноидов (III) \\ смесями бинарных экстрагентов - \\ карбоксилатов и диалкилфосфатов аминов}

\section{С.Н. Калякин,}

Институт химии и химической технологии СО РАН Россия, 660036, Красноярск, Академгородок, 50-24

Исследовано применение бинарных экстрагентов на основе карбоксилатов, ди-(2-этилгексил) фосфатов вторичных и третичных аминов и их смесей для разделения ионов лантаноидов (III). Изотермы экстракции нитратов лантаноидов(III) линейны на начальном участке, межфазный переход катиона и аниона неорганической соли является сопряженным, реэкстракиия лантаноидов может быть осуществлена водой. Изученные бинарные экстрагенть характеризуются высокими коэффициентами разделения лантаноидов. Обнаружень синергетические эффекты для систем ди-(2-этилгексил)фосфат-, капринат- диоктиламина и триоктиламина.

Ключевые слова: РЗМ, бинарная экстракиия, карбоксилаты, амины, Д2ЭГФК, синергетический эффект.

\section{Введение}

Бинарные экстрагенты на основе ди-(2-этилгексил) фосфорной кислоты (Д2ЭГФК) и органических аминов являются перспективными системами для создания новых методов разделения РЗМ. Бинарные экстрагенты представляют собой соли, образованные высокомолекулярными органическими катионами и анионами, то есть могут быть приготовлены на основе стехиометрических смесей известных катионо- и анионообменных экстрагентов [1]. Подобные системы часто относят к группе ионных жидкостей [2], однако бинарные экстрагенты, как правило, включают в состав органический разбавитель. Для бинарных экстрагентов обычно сохраняется селективность катионного и анионного обмена, характерная для исходных ионообменных экстрагентов, однако появляются новые свойства, обусловленные тем, что при извлечении неорганических солей межфазный перенос катиона и аниона сопряженный [3].

Известно, что экстрагенты на основе Д2ЭГФК наиболее селективны при разделении РЗМ [4]. Для бинарных экстрагентов на основе Д2ЭГФК и различных органических аминов и четвертичных аммониевых оснований высокая избирательность при экстракции солей РЗМ сохраняется. Однако проявляется недостаток экстрагентов на основе Д2ЭГФК - образование малорастворимых продуктов при концентрации РЗМ в органической фазе выше сотых долей моль/л.

Нами было установлено, что эффективной сольватирующей добавкой, повышающей растворимость ди-(2-этилгексил)фосфатов лантаноидов, выступают карбоновые кислоты и их соли с органическими аминами - карбоксилаты. Однако карбоксилаты аминов также способны 
экстрагировать соли РЗМ по механизму бинарной экстракции, при этом селективность экстракции РЗМ карбоновыми кислотами значительно ниже в сравнении с фосфорсодержащими экстрагентами. Селективность экстракции смесями диалкилфосфатов и карбоксилатов аминов определяется конкурирующими процессами извлечения ионов металлов двумя экстрагентами и специфическими процессами сольватации в органической фазе и в общем случае может быть установлена только на основании экспериментальных данных.

В предыдущих статьях нами были описаны особенности экстракции хлоридов РЗМ смесями бинарных экстрагентов [5-7]. Учитывая многообразие взаимодействий в органической фазе, поведение хлоридных и нитратных систем может значительно различаться. Цель представленной работы - изучение экстракции нитратов лантаноидов(III) бинарными эстрагентами на основе ди-(2-этилгекил)фосфатов диоктиламина либо триоктиламина и капринатов аминов, а также смесями указанных экстрагентов.

\section{Материалы и методы}

Бинарные экстрагенты ди-(2-этилгексил)фосфат триоктиламмина $\left(R_{3} N H A\right)$, ди-(2этилгексил)фосфат диоктиламина $\left(R_{2} \mathrm{NH}_{2} A\right)$ готовили растворением эквимолярных количеств Д2ЭГФК и соответствующего амина в толуоле. Аналогично готовили и бинарные экстрагенты на основе капринатов аминов; далее по тексту указанные экстрагенты будут обозначаться: капринат триоктиламина $\left(\mathrm{R}_{3} \mathrm{NHB}\right)$, капринат диоктиламина $\left(\mathrm{R}_{2} \mathrm{NH}_{2} \mathrm{~B}\right)$.

Экстракционные равновесия изучали при температуре $(25 \pm 1){ }^{\circ} \mathrm{C}$. Экстракцию и реэкстракцию проводили в делительных воронках при равном соотношении объемов органической и водной фаз. Продолжительность перемешивания фаз составляла 10 мин при времени установления равновесия в системе 3-5 мин.

При исследовании селективности экстракционного извлечения лантаноидов использовали растворы, содержащие сумму нитратов лантаноидов с одинаковой молярной концентрацией каждого из 14 металлов. Для растворов, содержащих только один лантаноид, концентрацию металла в исходном растворе и равновесной водной фазе определяли комплексонометрическим методом [8]. В случаях экстракции смеси лантаноидов анализ концентраций элементов в водных фазах осуществляли методом масс-спектрометрии с индукционно связанной плазмой на приборе ICP-MS Agilent 7500A.

Для определения $\mathrm{pH}$ растворов и других потенциометрических измерений применяли $\mathrm{pH}$ метр-иономер «Эксперт-001».

\section{Результаты и обсуждение}

В ранее представленных нами исследованиях [5-7] показано, что процесс извлечения неорганических солей РЗМ (хлоридов, бромидов, нитратов) ди-(2-этилгексил)фосфатами вторичных, третичных органических аминов и четвертичных органических оснований происходит в соответствии с закономерностями бинарной экстракции. Экстракция нитратов РЗМ ди-(2этигексил)фосфатами органических аминов (в частности, диоктиламина, триоктиламина) может быть описана следующим уравнением основной гетерогенной реакции (без учета специфических взаимодействий в органической фазе, например, процессов сольватации продуктов избытком экстрагента): 


$$
L n_{(8)}^{+3}+3 \mathrm{NO}_{3(6)}^{-}+3 R_{x} N H_{(4-x)}^{-} A_{(o)} \leftrightarrows \operatorname{LnA}_{3(o)}+3 R_{x} N H_{(4-x)} N O_{3(o)}
$$

где $R_{x} N H_{(4-x)} A$ - ди-(2-этилгексил)фосфат диоктиламина либо триоктиламина, символы (о) и (в) обозначают принадлежность к органической и водной фазе соответственно.

В случае, если экстракция нитратов РЗМ карбоксилатами аминов также происходит в соответствии с процессом бинарной экстракции, система может быть описана уравнением гетерогенной реакции:

$$
\mathrm{Ln}_{(\theta)}^{+3}+3 \mathrm{NO}_{3(8)}^{-}+3 R_{x} \mathrm{NH}_{(4-x)} B_{(o)} \leftrightarrows \mathrm{LnB}_{3(o)}+3 R_{x} \mathrm{NH}_{(4-x)} \mathrm{NO}_{3(o)},
$$

где $R_{x} N H_{(4-x)} B$ - карбоксилат диоктиламина либо триоктиламина.

Бинарная экстракция солей в сравнении с другими типами экстракционных процессов (катионообменным, сольватным) характеризуется рядом отличающихся концентрационных зависимостей:

- изотермы межфазного распределения экстрагируемых неорганических солей линейны в области низких концентраций (в отсутствие добавок в водной фазе других солей) и не зависят от рН для слабокислых и нейтральных водных растворов;

- для экстрагируемой неорганической соли межфазный переход катиона и аниона происходит в их стехиометрическом соотношении. Экстракция неорганических катионов зависит от концентрации сопряженных анионов в водной или органической фазах («эффект высаливания»).

При экстракции солей лантаноидов капринатами вторичных и третичных аминов, а также смесями указанных экстрагентов с ди-(2-этилгексил)фосфатами аминов линейная форма изотерм межфазного распределения наблюдается в широком диапазоне концентраций (рис. 1).

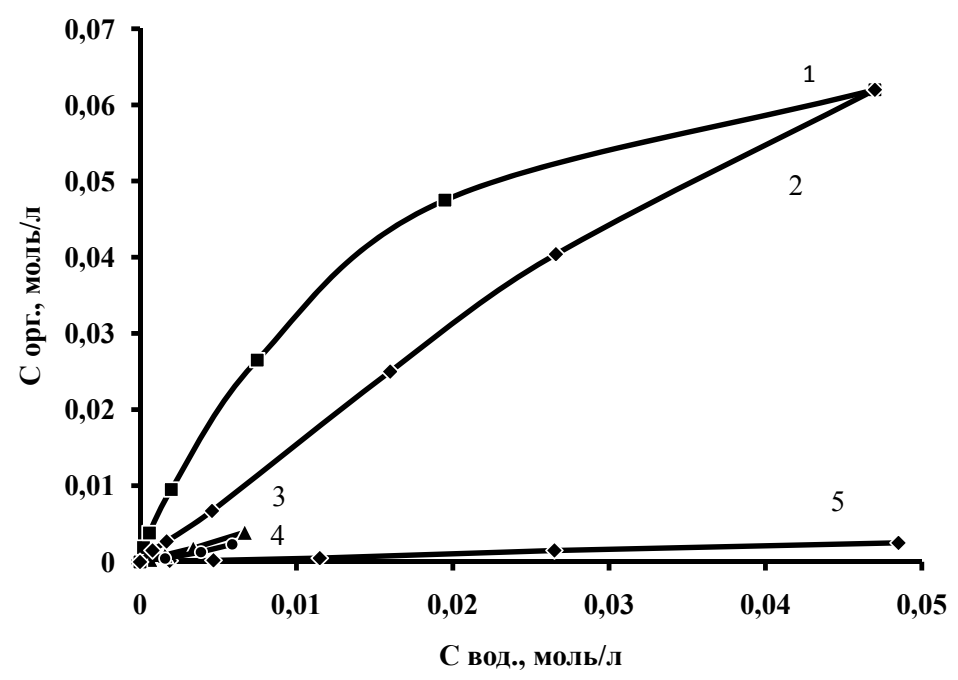

Рис. 1. Изотермы экстракции $\mathrm{La}\left(\mathrm{NO}_{3}\right)_{3}$ различными бинарными экстрагентами, разбавитель толуол: 1 - смешанный бинарный экстрагент 0,1 моль/л Д2ЭГФК - 0,3 моль/л каприновой кислоты - 0,4 моль/л диоктиламина; 2 - смешанный экстрагент 0,1 моль/л Д2ЭГФК - 0,3 моль/л каприновой кислоты - 0,4 моль/л N,N - диоктилметиламина; 3 - 0,1 моль/л Ди-(2-этилгексил)фосфат диоктиламмония; 4 - 0,1 моль/л Ди-(2-этилгексил)фосфат триалкиламмония; 5 - 0,3 моль/л каприновая кислота

$$
-583-
$$


Уменьшение наклона изотерм распределения в области высоких концентраций очевидно связано с изменением равновесной концентрации экстрагента. При этом для представленного диапазона концентраций и составов образование малорастворимых соединений в органической фазе не наблюдается. В ходе экстракции рН водной фазы (исходное значение 5,4 ) изменяется (уменьшается) менее чем на 0,4 .

Для карбоксилатов аминов в случае бинарной экстракции солей лантаноидов добавление нитрата амина в органическую фазу должно сопровождаться уменьшением коэффициентов распределения лантаноидов. Этот эффект имеется (рис. 2). Таким образом, экстракция нитратов лантаноидов (III) растворами карбоксилатов вторичных или третичных аминов происходит в соответствии с закономерностями бинарной экстракции, по крайне мере на качественном уровне. Вместе с тем количественное описание такого рода процессов, как правило, непростое, поскольку извлечение сопровождается различными побочными взаимодействиями в органической фазе, которые влияют на экстракционные зависимости.

В случае относительно низких концентраций экстрагируемых металлов в органической фазе, по-видимому, наиболее значимым дополнительным взаимодействием в органической фазе является сольватация органической соли металлов избытком бинарного экстрагента с образованием $\left(L n A_{3}\right) \cdot\left(N R_{x} H_{(4-x)} A\right)_{\mathrm{s}}$. В этом случае уравнение (1), как и (2), может быть преобразовано к виду

$$
L n_{(a q)}^{+3}+3 N O_{3(a q)}^{-}+(3+s) \cdot N R_{x} H_{(4-x)} A_{(o)} \leftrightarrows\left(L n A_{3(o)}\right) \cdot\left(N R_{x} H_{(4-x)} A\right)_{s}+3 N R_{x} H_{(4-x)} N O_{3(o)},
$$

где $\mathrm{s}$ - сольватное число.

Кроме указанного процесса возможна сольватация органических солей лантаноидов нитратами аминов, однако при этом исключается эффект подавления экстракции металлов при добавлении в органическую фазу нитрата амина (рис. 2). Также необходимо отметить, что в

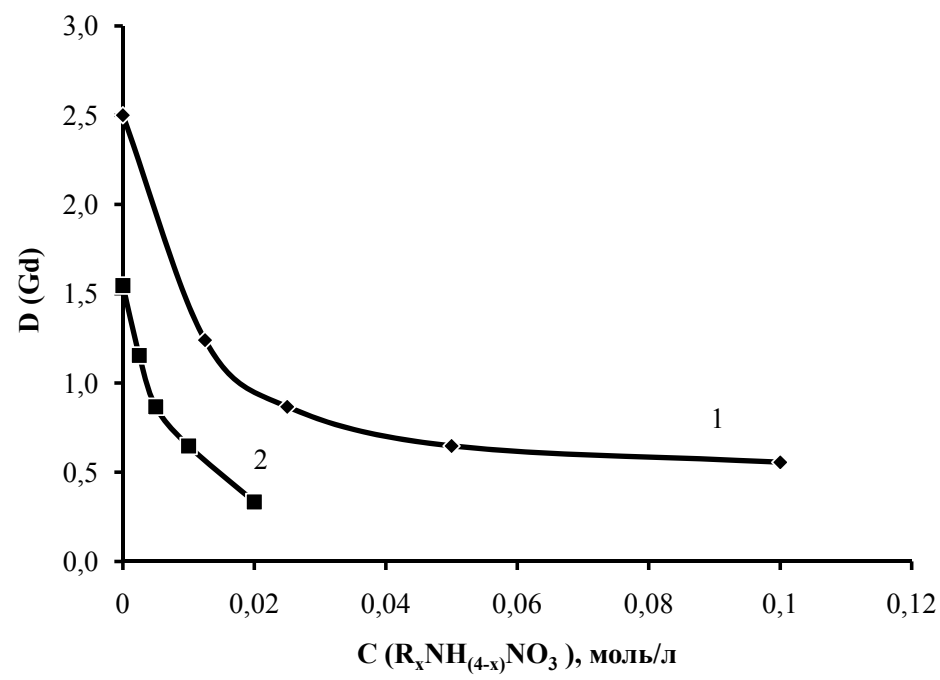

Рис. 2. Зависимость $\mathrm{D}_{\mathrm{Gd}}$ от концентраций нитрата амина в органической фазе, $\mathrm{C}\left(\mathrm{Gd}\left(\mathrm{NO}_{3}\right)_{3}\right)=0,0028$ моль/л: 1 - 0,5 моль/л капринат триоктиламмония в толуоле $-\mathrm{Gd}\left(\mathrm{NO}_{3}\right)_{3}$ с добавлением $\mathrm{NR}_{3} \mathrm{HNO}_{3} ; 2-0,1$ моль/л капринат диоктиламония в толуоле $-\mathrm{Gd}\left(\mathrm{NO}_{3}\right)_{3}$ с добавлением $\mathrm{NR}_{2} \mathrm{H}_{2} \mathrm{NO}_{3}$ 
неполярных растворителях для солей органических аминов всегда имеет место их самоассоциация.

Условная константа равновесия гетерогенной реакции (3) (без учета коэффициентов активностей ионов и соединений в водной и органической фазе) может быть записана в виде

$$
K_{e x}=\frac{\left[L n A_{3} \cdot\left(N R_{x} H_{(4-x)} A\right)^{s}\right]_{(o)} \cdot\left[R_{x} N H_{(4-x)} N O_{3}\right]_{(o)}^{3}}{\left[\operatorname{Ln}^{+3}\right]_{(a q)} \cdot\left[N O_{3}^{-}\right]_{(a q)}^{3} \cdot\left[R_{x} N H_{(4-x)} A\right]_{(o)}^{(3+s)}} .
$$

Для случая большого избытка экстрагента и отсутствия высаливателей в водной фазе (нитраты других металлов) нетрудно получить зависимости коэффициентов распределения металлов $\left(D_{L n}\right)$ от концентрации бинарного экстрагента (5) и (6):

$$
D_{L n}=K_{e x}^{\frac{1}{4}} \cdot\left[R_{x} N H_{(4-x)} A\right]^{3+s} 4 .
$$

Установлено, что для всех изученных нами экстракционных систем увеличение концентрации бинарных экстрагентов в органическом разбавителе сопровождается увеличением $D_{L n}$ (в полном соответствии с уравнением (5)). При этом концентрационные зависимости имеют степенной вид с коэффициентом в диапазоне $1-2$. Для расчета чисел сольватации и констант экстракционного равновесия применена функция (6), для которой численным методом минимизированы значения для наборов экспериментальных значений $D_{L n}$ при различных составах экстрагентов:

$$
f=\sum_{i=1}^{n}\left(\left(K_{e x}^{\frac{1}{4}} \cdot\left[R_{x} N H_{(4-x)} A\right]_{i}^{\frac{3+s}{4}}-D_{L n_{i}}\right)^{2} / D_{L n_{i}}\right) .
$$

В диапазоне концентраций экстрагентов [0-0,1 моль/л] при исходной концентрации $G d\left(\mathrm{NO}_{3}\right)_{3}$ в водной фазе 0,0028 моль/л рассчитанные сольватные числа превышают единицу, соответственно для всех исследованных систем экстрагируемые соединения гадолиния в органической фазе сольватированы избытком экстрагента. Для систем с ди-(2-этилгексил)фосфатом триоктиламина и капринатом диоктиламина органическая соль металла сольватирована тремя молекулами экстрагента, для ди-(2-этилгексил)фосфата диоктиламина характерен дисольват и каприната триоктиламина моносольват. Необходимо отметить, что при образовании устойчивых ассоциатов в органической фазе $\left(N R_{x} H_{(4-x)} N O_{3}\right)\left(N R_{x} H_{(4-x)} A\right)$ сольватные числа должны были быть много больше.

Так как продукты экстракции сольватированы избытком экстрагента, то в случае смешанных бинарных экстрагентов $\left(N R_{x} H_{(4-x)} B, N R_{x} H_{(4-x)} A\right)$ в системе можно ожидать образование более сложных сольватов и появление синергетических эффектов.

Для смесей двух бинарных экстрагентов при их различном соотношении и суммарной концентрации 0,1 моль/л в случае ди-(2-этилгексил)фосфатов и капринатов вторичного амина коэффициенты распределения солей лантаноидов имеют много большие значения, чем суммы коэффициентов распределения для отдельных экстрагентов при той же концентрации (рис. 3 , кривая 1). Наиболее значительный синергетический эффект наблюдается при соотношении указанных экстрагентов 1:2. Положительный синергетический эффект в данной экстракционной системе может быть объяснен на основании предположения, что ди-(2-

$$
-585-
$$


этилгексил)фосфат вторичного амина лучше сольватирует продукты экстракции в сравнении с карбоксилатом.

Для подобных смесей бинарных экстрагентов на основе третичного амина наблюдается отрицательный синергетический эффект (рис. 3, кривая 2). Кроме того, для систем с третичным амином характерны меньшие коэффициенты распределения солей (рис. 1) и меньшие числа сольватации. По-видимому, это объясняется стерическими затруднениями образования сложных ассоциатов в органической фазе.

Для всех изученных экстрагентов и их смесей при извлечении неорганических солей, образованных нитрат-ионом и различными лантаноидами, наблюдается возрастание коэффициентов распределения с увеличением порядкового номера металла (рис. 4). Указанные зависимости не монотонны, на них наблюдается несколько изломов (так называемый дубльдубль-эффект), характерных для многих катионообменных экстрагентов. Экстрагент на основе только ди-(2-этилгексил)фосфата диоктиламина обладает наибольшей селективностью, особенно для тяжелых лантаноидов. Для смесей экстрагентов на основе ди-(2-этилгексил)фосфатов и карбоксилатов диоктиламина селективность соизмерима с карбоксилатом диоктиламина и в общем случае, вероятно, определяется тем экстрагентом, для которого в индивидуальном виде реализуются более высокие коэффициенты распределения металлов. Для всех исследованных нами экстрагентов наблюдаются относительно высокие коэффициенты разделения пар лантаноидов (табл. 1), достаточные для применения предложенных экстрагентов в экстракционных технологиях разделения РЗМ.

В качестве примера использования бинарных экстрагентов для разделения РЗМ приведены модельные профили распределения по противоточному экстракционному каскаду двух металлов с коэффициентом экстракционного разделения 1,5 (рис. 5). При создании математиче-

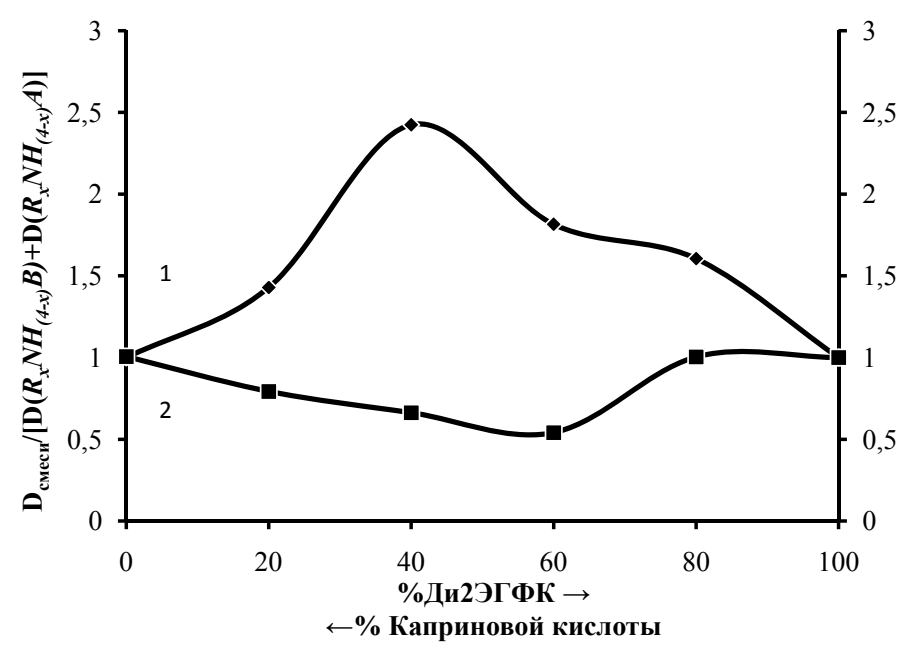

Рис. 3. Синергетические эффекты в смесях бинарных экстрагентов на основе диоктиламина (1) и триоктиламина (2). По оси абсцисс - соотношение в смешанном экстрагенте каприната и ди-(2этилгексил)фосфата амина, по оси ординат - отношение коэффициента распределения $\operatorname{Gd}\left(\mathrm{NO}_{3}\right)_{3}$ $\left(\mathrm{C}_{\text {вод.исх. }}=0,00345\right.$ моль/л) для смешанного экстрагента $-\mathrm{D}_{\text {смеси }}\left(\mathrm{C}_{\text {амина }}=0,1\right.$ моль/л), к сумме коэффициентов распределения для индивидуальных экстрагентов $-\mathrm{D}\left(R_{x} N H_{(4-x)} B\right)+\mathrm{D}\left(N R_{x} H_{(4-x)} A\right)$

$$
-586-
$$


Таблица 1. Коэффициенты разделения $(\beta \mathrm{Ln} / \mathrm{La})$ от порядкового номера элемента. $\Sigma\left[\operatorname{Ln}^{3+}\right]=2 \cdot 10^{-3}$ моль/л

\begin{tabular}{|c|c|c|c|c|}
\hline & $\mathrm{R}_{2} \mathrm{NH}_{2} \mathrm{~A}$, & $\mathrm{R}_{2} \mathrm{NH}_{2} \mathrm{~B}$, & $\mathrm{R}_{2} \mathrm{NH}_{2} \mathrm{~A}, 0,1$ моль/л & $\mathrm{R}_{3} \mathrm{NHA}, 0,1$ моль/л \\
\hline & 0,1 моль/л & 0,1 моль/л & $\mathrm{R}_{2} \mathrm{NH}_{2} \mathrm{~B}, 0,3$ моль/л & $\mathrm{R}_{3} \mathrm{NHB}, 0,3$ моль/л \\
\hline $\mathrm{La}$ & $\beta_{\text {цn/La }}$ & $\beta_{\text {Ln/La }}$ & $\beta_{\text {Ln/La }}$ & $\beta_{\text {Ln/La }}$ \\
\hline $\mathrm{Ce}$ & 1 & 1 & 1 & 1 \\
\hline $\mathrm{Pr}$ & 1,8 & 1,6 & 3,3 & 2,2 \\
\hline $\mathrm{Nd}$ & 2,55 & 1,85 & 7,75 & 6,35 \\
\hline $\mathrm{Sm}$ & 2,6 & 1,9 & 7,8 & 17,1 \\
\hline $\mathrm{Eu}$ & 3,8 & 3,3 & 19,2 & 18,1 \\
\hline $\mathrm{Gd}$ & 7,3 & 3,8 & 20,2 & 19 \\
\hline $\mathrm{Tb}$ & 8,4 & 4,1 & 20,7 & 27,7 \\
\hline $\mathrm{Dy}$ & 26,4 & 5,7 & 27,3 & 32,2 \\
\hline $\mathrm{Ho}$ & 54,8 & 6,2 & 30,3 & 37,4 \\
\hline $\mathrm{Er}$ & 68 & 7,2 & 37,4 & 89,2 \\
\hline $\mathrm{Tm}$ & 249 & 8,3 & 62,6 & 136 \\
\hline $\mathrm{Yb}$ & 1328 & 11,4 & 92,7 & 247 \\
\hline $\mathrm{Lu}$ & 2090 & 15,5 & 132,9 & \\
\hline
\end{tabular}

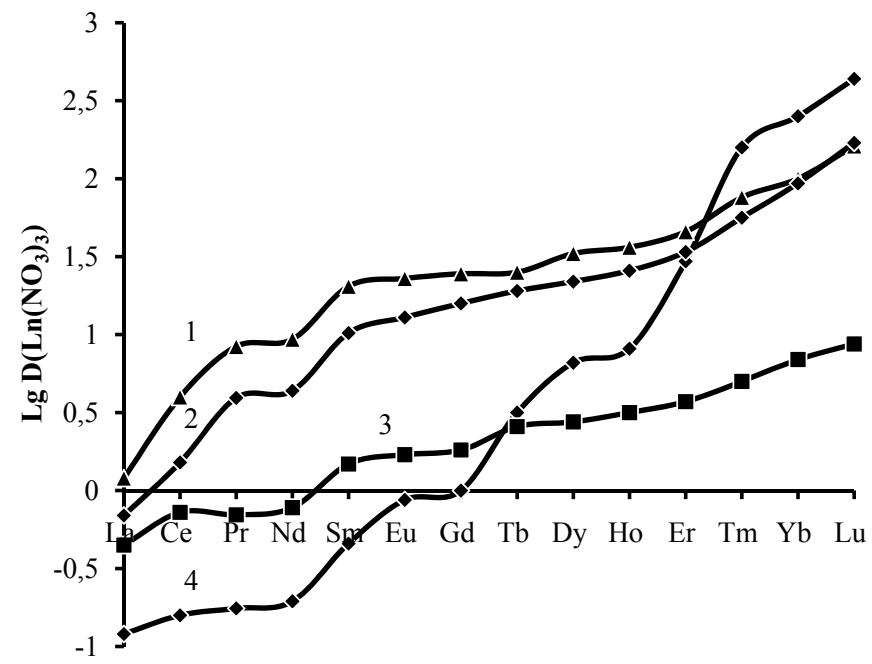

Рис. 4. Зависимость логарифма коэффициента распределения (D) от порядкового номера лантаноида, разбавитель толуол: $1-0,1$ моль/л ди-(2-этилгексил)фосфат диоктиламмония $+0,3$ моль/л капринат диоктиламмония; 2 - 0,1 моль/л ди-(2-этилгексил)фосфат триоктиламмония $+0,3$ моль/л капринат триоктиламмония; 3 - 0,1 моль/л капринат диоктиламмония; 4 - 0,1 моль/л ди-(2-этилгексил)фосфат диоктиламмония 
a)

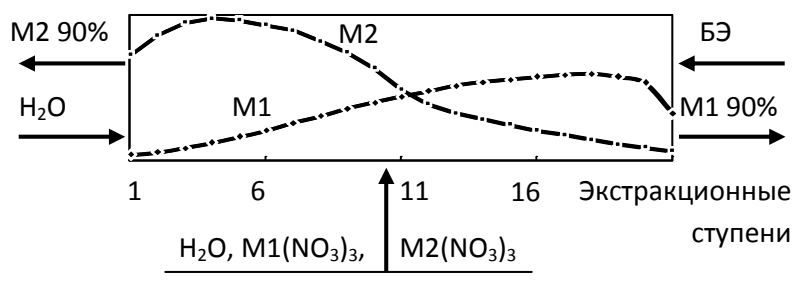

б)

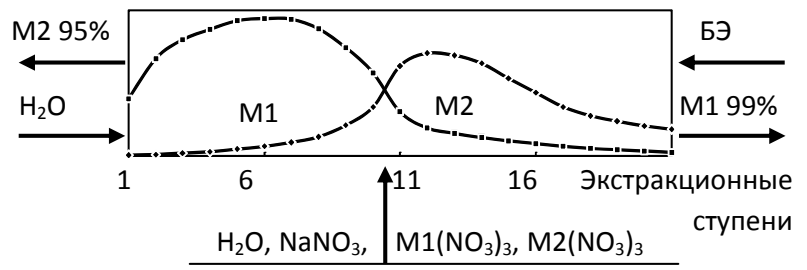

Рис 5. Применение бинарных экстрагентов в противоточных экстракционных каскадах. Число экстракционных ступеней 20 , смесь разделяемых металлов M1, M2 направляется в 10 -й экстрактор, $\beta \mathrm{M} 1 /$ M2=1,5, тяжелая фаза - ионизованная вода: $\mathrm{a}-$ без введения высаливателей; б - с высаливателем

ской модели противоточного каскада с использованием в качестве одной из разделяющих фаз бинарных экстрагентов применены положения, приведенные в статье [3]. В представленной модели в качестве второй разделяющей фазы выступает деионизованная вода (рис. $5 a$ ) либо раствор электролита, содержащий одноименный с экстрагируемыми солями металлов анион (рис. 5б). Смесь солей разделяемых металлов с водной фазой поступает в среднюю часть каскада. При этом управление каскадом, в частности изменение направления движения выделяемого металла по экстракционным ступеням, становится возможным достичь не только изменением соотношения потоков фаз, но и введением высаливающих добавок (электролитов, содержащих сопряженный анион) в различные ступени каскада. Например, при введении высаливателей $\left(\mathrm{NaNO}_{3}\right)$ в среднюю часть каскада удается скорректировать форму изотерм распределения металлов на отдельных ступенях и получить металлы на выходе 99 и 95\%-ной чистоты, практически приближаясь к теоретической эффективности разделения двух катионов на 20 ступенях противоточного экстракционного каскада при коэффициенте разделения на каждой ступени 1,5 .

\section{Выводы}

Установлено, что извлечение нитратов РЗМ растворами в органических разбавителях каприната диоктиламина и триоктиламина (а также и для их смесей с ди-(2-этилгексил)фосфатами аминов) происходит в соответствии с закономерностями бинарной экстракции солей:

- изотермы межфазного распределения неорганических солей имеют линейный вид на начальном участке (в области низких концентраций) и выходят на насыщение при уменьшении концентрации свободного экстрагента. В процессе экстракции рН водной фазы изменяется незначительно в диапазоне 5,0-5,4;

- при введении в органическую фазу нитратов соответствующих аминов происходит подавление экстракции нитратов РЗМ капринатами аминов (эффект высаливания).

Продукты экстракции в органической фазе сольватированы избытком бинарного экстрагента, это в случае смесей нескольких бинарных экстрагентов может приводить к значитель- 
ным положительным синергетическим эффектам, что наблюдается для системы капринат, ди(2-этилгексил)фосфат диоктиламмония.

Селективность извлечения РЗМ смесями бинарных экстрагентов в общем случае определяется тем экстрагентом, который имеет более высокие коэффициенты экстракции в индивидуальном виде. Для исследованных нами смесей бинарных экстрагентов селективность экстракции снижается по сравнению экстрагентами только на основе ди-(2-этилгексил)фосфатов аминов, однако при этом одновременно происходит повышение растворимости экстрагируемых соединений и снижение гелеобразования.

Для исследованных смесей бинарных экстрагентов селективность извлечения РЗМ достаточна для их разделения с применением противоточных экстракционных каскадов.

\section{Список литературы}

1. Холькин А. И., Кузьмин В. И., Пашков Г. Л. и др. Бинарная экстракции и перспективы ее применения. Изв. Сиб. отд. АН СССР. Сер. хим. наук 1990. Вып. 5. С. 3-17. [Khol'kin А. I., Kuz'min V. I., Pashkov G. L et al. Binary extraction and perspectives for its application. Math. Sib. Dep. USSR Academy of Sciences. Ser. chem. Sciences 1990. (5), P. 3-17. (In Russ.)]

2. Villemin D. and Didi M. A. Extraction of rare earth and heavy metals, using ionic solvents as extraction medium (A Review). Oriental Journal of chemistry 2013. Vol. 29 (4), P. 1267-1284.

3. Kalyakin S.N., Kuz'min V.I. Binary extracting agents as new stationary phases for the extraction chromatography of ionic compounds. Mendeleev Communications 2000. Vol. 4, P. 151-152.

4. Khaironie M.T., Masturah M., Meor Yusoff M.S., Nazaratul Ashifa S. Solvent Extraction of Light Rare Earth Ions Using D2EHPA from Nitric Acid and Sulphuric Acid Solutions. Advanced Materials Research 2014. Vol. 970, P. 209-213.

5. Калякин С. Н., Кузьмин В. И., Мулагалеева М. А. Бинарная экстракция хлоридов лантана и церия(III) ди-(2-этилгексил)фосфатом тетраоктиламмония. Химическая технология 2001. T.1. C. 23-27. [Kalyakin S.N., Kuz'min V.I., Mulagaleeva M.A. Binary extraction of lanthanum and cerium(III) chlorides with tetraoctylammonium and di-(2-ethylhexyl)phosphate. Russian Journal Chemical Technology. 2001. Vol. 1, P. 23-27. (In Russ.)]

6. Kalyakin S.N., Kuz'min V.I., Mulagaleeva M.A. Binary extraction of lanthanide(III) chlorides using carboxylates and dialkylphosphates of secondary and tertiary amines. Hydrometallurgy 2015. Vol. 151, P. 116-121.

7. Калякин С. Н., Кузьмин В. И., Мулагалеева М. А. Применение бинарных экстрагентов на основе ди-(2-этилгексил)фосфорной кислоты для разделения лантаноидов. Цветные металль 2011. T.3. C. 51-54. [Kalyakin S.N., Kuzm'in V.I., Mulagaleeva M.A. The use of binary agents based on di-(2-ethylhexyl)phosphoric acid for lanthanides separation. Russian Journal Nonferrous Metal. 2011. Vol. 3, P. 51-54. (In Russ.)]

8. Пршибил Р. Аналитическое применение этилендиаминтетрауксусной кислоты. М.: Мир, 1975. 531 c. [Prshibil R. Analytical Application of Ethylenediaminetetraacetic Acid. Moscow: Mir, 1975. 531 p. (In Russ.)] 